\title{
EVALUASI TEGANGAN-REGANGAN DENGAN PEMODELAN SILINDER BETON
}

\author{
Ming Narto Wijaya \\ Dosen / Jurusan Teknik Sipil / Universitas Brawijaya \\ Korespondensi: mingnw@ub.ac.id
}

\begin{abstract}
Compressive strength is one of the main parameters in the analysis of concrete behavior. In general, the compressive strength of the concrete will be tested in the laboratory using the Uniaxial Compression Test tool. However, it requires a lot of energy and cost and a long time. For that we need an approach with a simulation of numerical methods that is with finite element method using ABAQUS aids program. Based on the results of numerical analysis, it is concluded that the modeling of concrete elements using ABAQUS element finite aids program can be done by creating $3 D$ solid model, using C3D8R element type and discrete rigid plate as pressure load suppliers. Furthermore, plastic material input is used in the form of Concrete Damaged Plasticity (CDP). While the stress-strain distribution in concrete modeling using ABAQUS auxiliary program shows the distribution according to laboratory test result, especially the elasticity modulus seen from the relationship curve of stress-strain strain. However, there is a difference in the maximum compressive strength achieved between the two tests. Therefore, further analysis is needed to know the properties of the concrete material used in the analysis, and the damage behavior that will influence the input of the material being analyzed.
\end{abstract}

Keywords : ABAQUS, C3D8R, discrete rigid, compressive strength, stress-strain

\section{PENDAHULUAN}

Secara umum, kuat tekan beton akan diuji di sebuah laboratorium untuk menentukan validitas dari kuat tekan yang direncanakan. Akan tetapi, hal tersebut akan memerlukan tenaga dan biaya yang besar, waktu yang lama, serta pelaksanaan yang sulit. Untuk itu dibutuhkan suatu pendekatan yang tidak membutuhkan biaya yang besar dan waktu yang lama. Salah satu pendekatan yang dapat dilakukan yakni pendekatan simulasi metode numerik yaitu dengan metode elemen hingga (finite element method).

Metode elemen hingga dapat digunakan untuk menyelesaikan berbagai permasalahan yang meliputi bentuk geometri, pembebanan yang sulit maupun material penyusun yang kompleks [1]. Beton memiliki material penyusun yang kompleks karena merupakan material yang bersifat elasto-plastis dengan perilaku ketidaklinearannya pada pembebanan awal hingga mencapai kekuatan batas.

Pemodelan numerik yang berbasis metode elemen hingga yang akan digunakan yakni program bantu ABAQUS. Pemilihan program ini didasari oleh kelebihannya yang dapat membuat geometry tegangan dan regangan yang terjadi pada material beton dengan lebih akurat, serta telah banyak digunakan oleh para engineer dari berbagai macam industri, seperti perusahanan pesawat terbang, automotif, perminyakan, mikroelektronik, dan juga laboratorium penelitian nasional pada berbagai universitas di dunia [2].

Hasil yang akan didapatkan dengan melakukan analisis numerik berbasis finite element ini akan divalidasi dengan hasil eksperimental dari 48 benda uji yang dilakukan di Laboratorium Struktur Jurusan Teknik Sipil Fakultas Teknik Universitas Brawijaya pada tahun 2017. 


\section{TINJAUAN PUSTAKA}

\subsection{Kuat Tekan Beton}

Kekuatan tekan beton fc' ditentukan oleh silinder standar yang dirawat dibawah kondisi standar laboratorium pada kecepatan pembebenan tertentu, pada umur 28 hari [3]. Pada pengujian kuat tekan beton yang menggunakan mesin tekan, benda uji diletakkan secara sentris pada bidang lingkarnya. Kemudian dilakukan pembebanan secara bertahap dan kecepatan peningkatan beban tertentu, hingga benda uji beton mengalami kehancuran.

$$
\begin{aligned}
& f c^{\prime}=P / A \\
& P=m . g
\end{aligned}
$$

Fc' pada persamaan diatas merupakan tegangan tekan tertinggi yang dicapai pada umur 28 hari akibat beban tekan selama masa percobaan. Tegangan yang dicapai bukanlah tegangan maksimum saat benda uji hancur, melainkan tegangan maksimum saat regangan beton mencapai $\pm 0,002$ [4].

\subsection{Hubungan Tegangan Regangan}

PBI 1971 melakukan percobaan kuat tekan benda uji beton pada umur 28 hari dengan berbagai macam mix design dan didapatkan hasil kurva tegangan-regangannya terdapat pada Gambar 1. Berdasarkan kurva tersebut dapat ditarik kesimpulan bahwa nilai tegangan fc' mencapai nilai maksimum saat regangan mencapai $\pm 0,002$ dan akan terus menurun sampai benda uji hancur pada nilai 0,003-0,005, serta kemiringan awal kurva akan bervariasi bergantung pada nilai kuat betonnya.

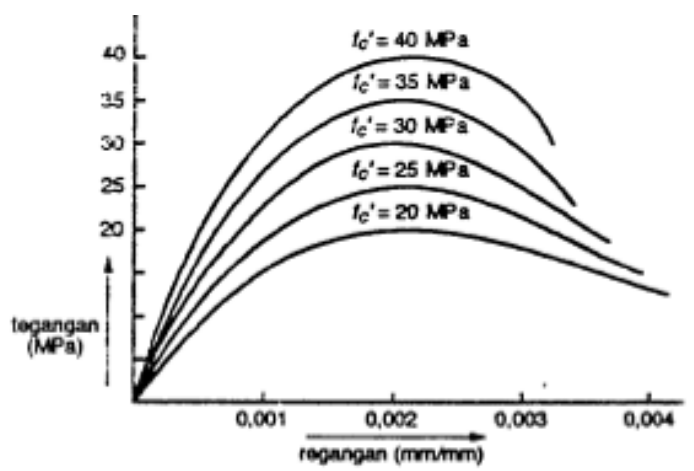

Gambar 1. Kurva hubungan tegangan-regangan

\subsection{Metode Elemen Hingga}

Metode elemen hingga merupakan metode numerikal untuk menyelesaikan permasalahan keteknikan dan fisika-matematik, termasuk juga analisis struktural, perpindahan panas, mekanika fluida, dan potensi elektromagnetik. Namun ketika permasalahan yang dibahas telah masuk ke suatu hal yang lebih kompleks seperti bentuk geometri dan pembebanan yang sulit, serta material penyusun yang heterogen maka penyelesaiannya sulit dikerjakan dalam analisis matematik. Sehingga, solusinya bukan lagi menggunakan turunan parsial ataupun persamaan umum, melainkan menggunakan persamaan aljabar. Sedangkan pada proses pemodelannya, kontinum dibagi menjadi unit-unit yang lebih kecil (finite element) pada suatu sistem keseimbangan dengan dua atau lebih titik dan garis batas maupun permukaan batas yang biasa disebut diskretisasi [1].

\subsection{Matriks 3-Dimensi}

Menurut Logan [1], untuk memodelkan suatu benda uji yang berbentuk 3 dimensi, maka teori yang digunakan adalah teori Three-Dimensional Stress Analysis. Analisis 3D ini digunakan karena dibutuhkannya analisis yang lebih akurat dibandingkan dengan analisis 2D ataupun analisis asimetris. Contoh dari 3D analisis ini adalah alat berat, bendungan, bagian-bagian dari mesin automotive, dan lain-lain.

Pada Gambar 2 ditunjukkan bahwa terdapat tiga komponen yang bekerja pada 3 sumbu yakni sumbu $x, y$, dan $z$.

Hubungan regangan pada elemen tersebut dapat ditunjukkan dengan persamaan (1).

$$
\varepsilon_{x}=\frac{\partial u}{\partial x} \quad \varepsilon_{y}=\frac{\partial v}{\partial y} \quad \varepsilon_{z}=\frac{\partial w}{\partial z}
$$

Kemudian, kita juga dapat merepresentasikan tegangan dan regangan dengan matriks kolom

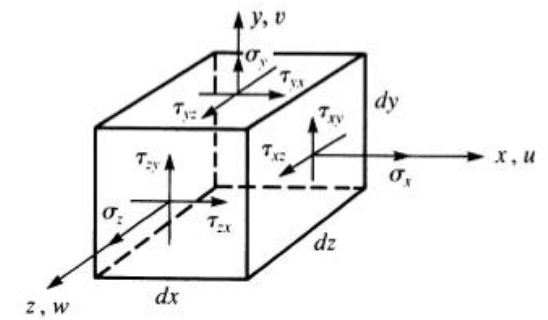

Gambar 2. Tegangan 3D yang terjadi pada suatu elemen 


$$
\{\sigma\}=\left\{\begin{array}{c}
\sigma_{x} \\
\sigma_{y} \\
\sigma_{z} \\
\tau_{x y} \\
\tau_{y z} \\
\tau_{z x}
\end{array}\right\} \quad\{\varepsilon\}=\left\{\begin{array}{c}
\varepsilon_{x} \\
\varepsilon_{y} \\
\varepsilon_{z} \\
\gamma_{x y} \\
\gamma_{y z} \\
\gamma_{z x}
\end{array}\right\}
$$

Sedangkan hubungan tegangan - regangan pada material isotropik adalah sebagai berikut

$$
\{\sigma\}=[\mathrm{D}]\{\varepsilon\}
$$

\subsection{Pemodelan Numerik Elemen Hingga}

Untuk mendapatkan perilaku nonlinear dari beton, maka perlu memodelkan elemen hingga 3D nonlinear untuk menganalisis beban tekan sampai kuat tekan ultimate dari benda uji itu sendiri. Pemodelan dengan ABAQUS ini menggunakan konsep kerusakan plastis beton (Concrete Damaged Plasticity) atau bisa disingkat CDP. Untuk mendapatkan informasi yang lebih rinci mengenai parameter dari konsep CDP ini, dapat ditemukan di buku panduan ABAQUS [5].

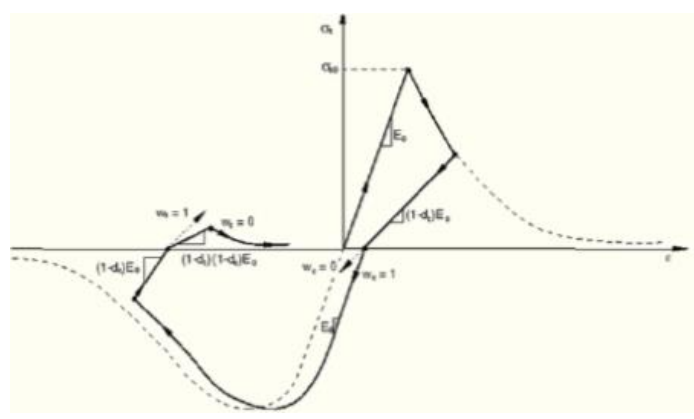

Gambar 3. Kurva tegangan-regangan pada beton dengan kerusakan plastis

Perilaku material beton dengan kuat tekan uniaksial dan kuat tarik konstitutif dibutuhkan untuk menentukan model CDP di program bantu ABAQUS. Hubungan tegangan-regangan dengan pembebanan uniaksial adalah:

$$
\sigma_{c}=\left(1-d_{c}\right) E_{0}\left(\varepsilon_{c}-\varepsilon_{c}^{p l}\right)
$$

dimana,

$$
\begin{aligned}
& E_{0}=\text { kekakuan elastis awal dari material } \\
& \varepsilon_{c}^{p l}=\text { tegangan plastis untuk kuat tekan } \\
& d_{c}=\text { variabel kerusakan }
\end{aligned}
$$

Terdapat beberapa parameter yang digunakan dalam menentukan variabel kerusakan, seperti yang ditampilkan pada Tabel 1.
Tabel 1. Parameter CDP untuk material beton dalam ABAQUS

\begin{tabular}{|c|c|c|}
\hline Parameter & Nilai & Keterangan \\
\hline$\Psi$ & $56^{\circ}$ & Sudut dilatasi \\
\hline$\epsilon$ & 0,1 & Eksentrisitas \\
\hline $\mathrm{K}$ & 0,667 & $\begin{array}{c}\text { Rasio tegangan kedua } \\
\text { yang tidak bervariasi } \\
\text { pada rata-rata tarik }\end{array}$ \\
\hline$\mu$ & 0,0001 & Parameter viskositas \\
\hline $\mathrm{fb}_{\mathrm{o}} / \mathrm{fc}_{\mathrm{o}}$ & 1,16 & $\begin{array}{c}\text { Rasio equibiaxial awal } \\
\text { dari kuat tekan tegangan } \\
\text { leleh dengan uniaksial } \\
\text { tekan tegangan leleh }\end{array}$ \\
\hline
\end{tabular}

\section{METODE PENELITIAN}

\subsection{Pengujian Bahan di Laboratorium}

Pengujian material dan benda uji dilakukan di Laboratorium Bahan dan Konstruksi Jurusan Teknik Sipil FTUB. Pengujian bahan meliputi uji berat jenis dan gradasi. Sedangkan pengujian silinder dan kubus beton meliputi uji kuat tekan dan uji tegangan-regangan menggunakan strain gauge. Hasil yang diperoleh nantinya akan dibandingkan dengan hasil analisis secara numerik dengan menggunakan ABAQUS.

Pada penelitian ini digunakan benda uji sejumlah 3 sampel untuk tiap mutu beton, seperti terlihat pada Tabel 2.

Tabel 2. Benda uji

\begin{tabular}{|l|l|c|c|c|c|}
\hline \multirow{2}{*}{ No. } & \multicolumn{1}{|c|}{ Benda Uji } & \multicolumn{4}{|c|}{ Mutu beton (f'c) } \\
\cline { 3 - 6 } & & $20 \mathrm{MPa}$ & $25 \mathrm{MPa}$ & $30 \mathrm{MPa}$ & $35 \mathrm{MPa}$ \\
\hline 1 & Kubus $15 \times 15 \times 15 \mathrm{~cm}$ & 3 buah & 3 buah & 3 buah & 3 buah \\
\hline 2 & Silinder $\mathrm{t}=30 \mathrm{~cm}, \mathrm{~d}=15 \mathrm{~cm}$ & 3 buah & 3 buah & 3 buah & 3 buah \\
\hline
\end{tabular}

\subsection{Variabel Penelitian}

Variabel yang dipakai dalam penelitian ini adalah sebagai berikut:

a. Variabel bebas (independent variable) yang digunakan pada penelitian adalah kuat tekan rencana beton, sebesar $20 \mathrm{MPa}$, $25 \mathrm{MPa}, 30 \mathrm{MPa}$, dan $35 \mathrm{MPa}$.

b. Variabel terikat (dependent variable) dalam penelitian ini adalah besarnya tegangan dan regangan beton.

\section{HASIL DAN PEMBAHASAN}

\subsection{Analisis dengan Eksperimen}

Pada penelitian ini mutu beton dibuat bervariasi dengan mutu $20 \mathrm{MPa}, 25 \mathrm{MPa}, 30$ $\mathrm{MPa}$, dan $35 \mathrm{MPa}$ dengan jumlah sampel 
sebanyak 3 buah untuk setiap mutunya. Hasil pengujian kuat tekan beton yang digambarkan dalam grafik hubungan antara teganganregangan beton, yang ditampilkan pada

\section{Gambar 4.}

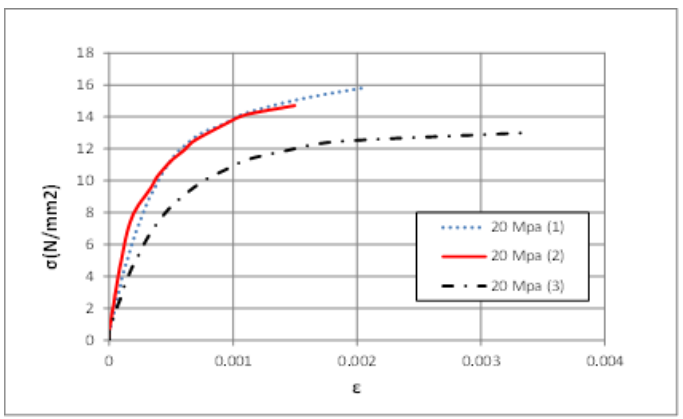

(a) Mutu beton $20 \mathrm{MPa}$

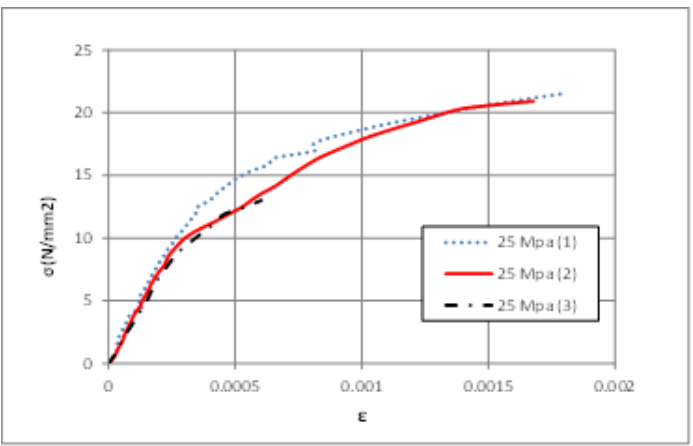

(b) Mutu beton $25 \mathrm{MPa}$

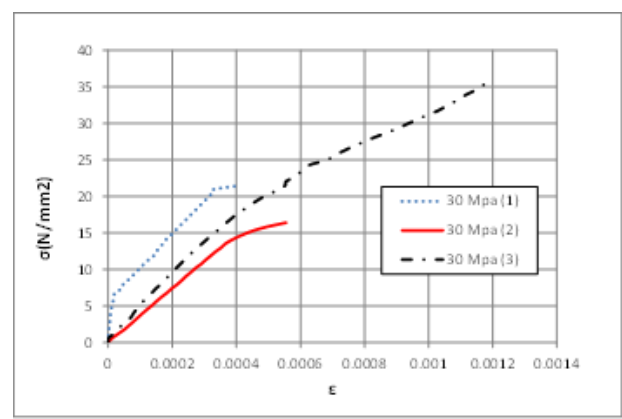

(c) Mutu beton $30 \mathrm{MPa}$

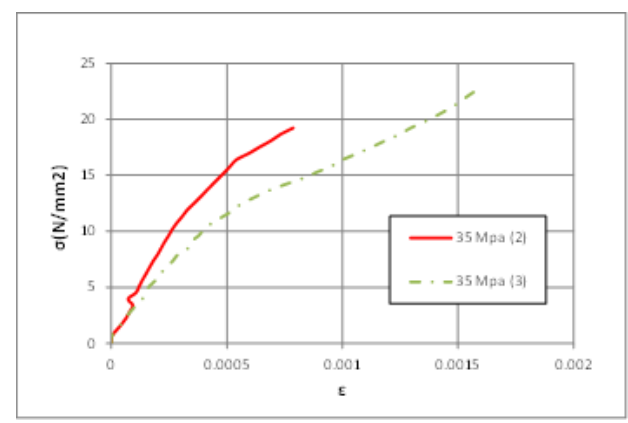

(d) Mutu beton $35 \mathrm{MPa}$

Gambar 4. Grafik hubungan antara tegangan-regangan pada benda uji silinder beton

Berdasarkan gambar tersebut dapat diketahui bahwa hasil antara hasil pengujian kuat tekan beton di laboratorium memiliki perbedaan dengan perencanaan. Hal tersebut dapat disebabkan karena kesalahan sewaktu melakukan mix desain maupun pencampuran beton, kondisi material/agregat yang dipakai tidak sesuai dengan perencanaan, waktu perendaman beton, dan sebagainya.

\subsection{Pemodelan Benda Uji Silinder Beton di ABAQUS}

Pemodelan secara numeric untuk silinder beton dengan ukuran diameter $15 \mathrm{~cm}$ dan tinggi $30 \mathrm{~cm}$ dilakukan dengan menggunakan software ABAQUS. Beton diidealisasikan menjadi material homogen dengan tipe C3D8R. "C3D8R elements with reduced integration were chosen because it follows the constitutive law integration accurately and very suitable for nonlinear static dynamic analyses as well as allow for finite strain and rotation in large-displacement analysis"

Pada penelitian ini digunakan kuat tekan beton f'c sebesar $20 \mathrm{MPa}, 25 \mathrm{MPa}, 30 \mathrm{MPa}$, serta $35 \mathrm{MPa}$. Properti material untuk silinder beton yang terdiri dari berat isi, modulus elastisitas (Young's Modulus), tegangan tarik (tensile stress), dan rasio poisson secara berurutan sebesar $2400 \mathrm{~kg} / \mathrm{m} 3,21019.04 \mathrm{MPa}$, $1.45 \mathrm{MPa}$, serta 0.18 . Sedangkan analisisnya menggunakan metode Concrete Damaged Plasticity, dengan input plastisitas untuk dilation angle, eccentricity, fbo/fco, K, serta viscosity parameter secara berurutan sebesar $30^{\circ}, 0.1,1.16,0.667$, dan 0 .

Perilaku kuat tekan dan kuat tariknya dapat dilihat Gambar 5 dan Gambar 6. Sedangkan bentuk pemodelan silinder beton beserta pembebanan dan meshing elemennya pada ABAQUS dapat dilihat pada Gambar 7 dan Gambar 8.

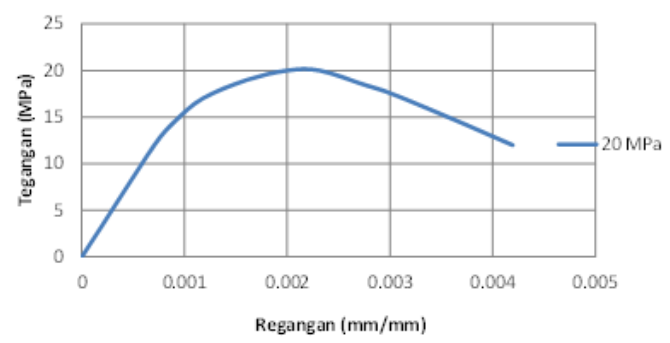

Gambar 5. Kurva tegangan - regangan beton (kuat tekan beton) 


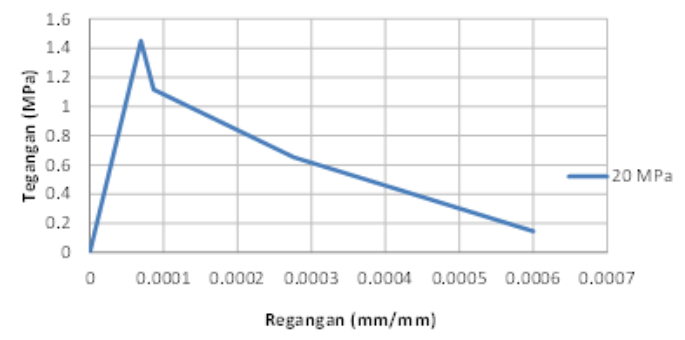

Gambar 6. Kurva tegangan - regangan beton (kuat tarik beton)

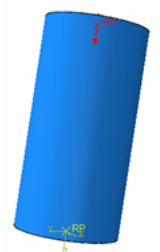

Gambar 7. Pemodelan beban pada silinder beton (input beban tekan)

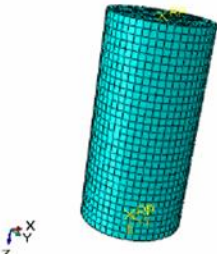

Gambar 8. Meshing pada model silinder beton

\subsubsection{Tegangan Tekan (Compression Stress)}

Hasil dari compression stress pada silinder beton yang telah dibebani dengan beban tekan dapat dilihat paga Gambar 9 berikut. Dari ilustrasi tersebut dapat diketahui bahwa tegangan tekan (S33) dan regangan tekan akan semakin besar nilainya pada bagian tengah silinder. Apabila tegangan yang terjadi melebihi tegangan ijinnya, maka beton akan mengalami kehancuran.

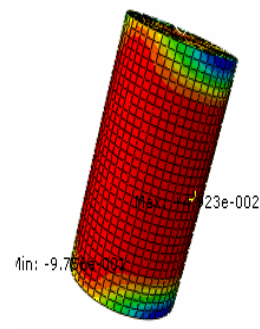

Gambar 9. Tegangan aksial pada beton

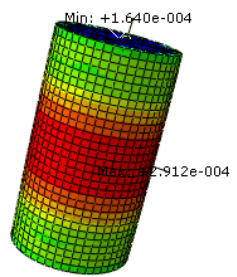

Gambar 10. Regangan aksial pada silinder beton

\subsubsection{Plastic Strain Magnitude (PEMAG)}

Visualisasi dari plastic strain magnitude (PEMAG) ditunjukkan pada Gambar 11. Berdasarkan gambar tersebut, dapat diketahui distribusi dari regangan plastis yang terjadi pada silinder beton.
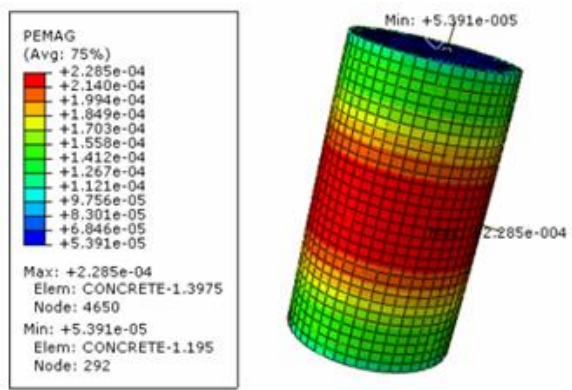

Gambar 11. Plastic strain magnitude (PEMAG)

\subsubsection{Kurva Tegangan - Regangan Beton}

Distribusi tegangan-regangan yang terjadi pada silinder beton ditampilkan pada Gambar 12.

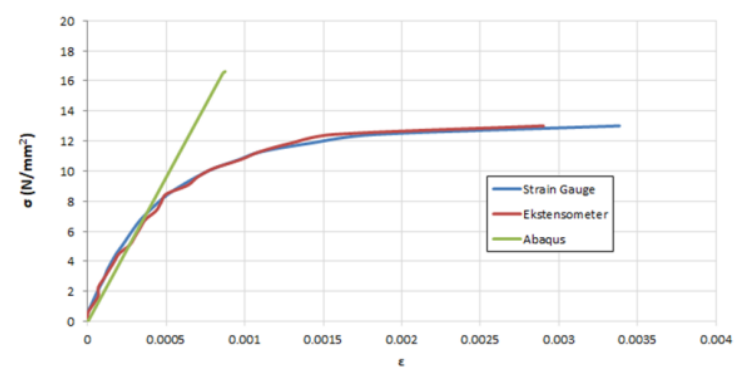

Gambar 12. Kurva tegangan-regangan beton

Berdasarkan gambar tersebut dapat diketahui bahwa modulus elastisitas pada silinder beton yang dianalisis pada ABAQUS bernilai hampir sama dengan hasil pengujian di laboratorium. Akan tetapi terjadi perbedaan pada tegangan plastisnya. Oleh karena itu, perlu dilakukan pengecekan ulang terhadap input data yang dimasukkan ke dalam analisis beserta properti materialnya dan input 
damage-nya. Akan tetapi jika dibandingkan dengan mutu beton yang dianalisis sebesar 20 $\mathrm{MPa}$, maka hasil analisis secara numerical menunjukkan hasil yang lebih mendekati dengan perencanaan.

\section{KESIMPULAN DAN SARAN}

Beberapa kesimpulan yang dapat diambil dari penelitian ini adalah sebagai berikut:

a. Pemodelan elemen beton menggunakan program ABAQUS dapat dilakukan dengan membuat model 3D solid, menggunakan tipe elemen C3D8R. Selanjutnya digunakan input material plasticity berupa Concrete Damaged Plasticity (CDP).

b. Hasil persebaran tegangan-regangan pada pemodelan beton dengan menggunakan program bantu ABAQUS menunjukkan distribusi yang sesuai dengan hasil pengujian di laboratorium, terutama besarnya modulus elastisitas yang terlihat dari kurva hubungan antara tegangan-regangan beton. Akan tetapi, terdapat perbedaan hasil kuat tekan maksimum yang dicapai antara kedua pengujian tersebut.

c. Analisis numerik kuat tekan beton dengan ABAQUS dapat dilakukan dengan membuat model 3D solid dengan tipe elemen C3D8R pada silinder beton. Kemudian pada bagian atas dan bawah silinder ditambahkan pemodelan berupa discrete rigid plate, yang berfungsi untuk menyalurkan beban tekan yang diberikan pada silinder beton.

d. Jika dibandingkan antara analisis numeric dan uji eksperimental, maka dapat diketahui bahwa pada analisis numeric terjadi kekuatan tekan yang lebih besar dibandingkan dengan hasil eksperimen. Akan tetapi, modulus elastisitas yang terjadi mempunyai nilai yang hampir sama.

\section{DAFTAR PUSTAKA}

[1] Logan, Daryl, A First Course in the Finite Element Method, Fourth Edition, Canada, 2007 : Thompson.

[2] Division of Engineering Brown University, ABAQUS tutorial, USA, 2007 : Brown University.

http://www.engin.brown.edu/course/En175. (diakses tanggal 18 Maret 2017).

[3] Nawy, Edward G., Beton Bertulang Suatu Pendekatan Dasar, Bandung, 1990 : PT ERESCO.

[4] Dipodusodo, Istimawan, Struktur beton bertulang, Jakarta, 1999 : PT.Gramedia Pustaka Utama

[5] Demir, A. Ozturk, H. \& Dok, G., Numerical Modeling of RC Deep Beam Behaviour by Nonlinear Finite Element Analysis, Disaster Science and Engineering II(1), 2016 : 13-18. 2016). 